Care must also be taken not to confound it with bromide of ethylen.

In regard to purity the most important point is the liability of the drug to undergo decomposition through exposure to light or air. It appears, also, that in the presence of a flame the vapour is decomposed, the excessively irritating vapours of free bromine being liberated. Impurities are apt to be present in the commercial article. From Dr. Kelly's excellent paper on Bromide of Ethyl Anæsthesia in the British Medical Journal of August 30th, 1902, p. 588, I give a passage quoted trom $\mathrm{Mr}$. J. P. Gilmour: "During the past three years I have examined 50 specimens of bromide of ethyl (bromethane) for Dr. A. B. Kelly, with the following results: 30 samples (60 per cent.) were utterly unfit for anæsthetic purposes owing to the presence of impurities due either to contamination in the process of manufacture or to decomposition by reason of age, presence of moisture, or exposure to light. Of the 50 specimens examined, 25 (50 per cent.) contained free hydrobromic acid; 2 (4 per cent.) free bromine; 20 (70 per cent.) had an odour of garlic due to the presence of phosphoretted hydrogen; 40 (80 per cent.) showed the presence of amyl and ethylene compounds; and 10 (20 per cent.) contained sulphur compounds." Dr. Kelly adds that Messrs. Duncan and Flockhart are now able to supply an absolutely pure preparation.

Pure bromide of ethyl is a colourless liquid with an ethereal oduur, free from garlic-like smell. Its specific gravity is from 1445 to 1450 and its boiling point is from $100.4^{\circ}$ to $104^{\circ} \mathrm{F}$. In Martindale's "Extra-Pharmacopoia" the specific gravity is erroneously given as 1419 and the boiling point as $105^{\circ} \mathrm{F}$. The garlic-like smell of some impure specimens, which Mr. Gilmour ascribes to phosphoretter hydrogen, is said by Loebisch in Eulenburg's "Real-Encyclopädie" to be due to ethyl sulphide. To avoid confusion some chemically related bodies may be placed in comparison : Bromide of ethyl, $\mathrm{C}_{2} \mathrm{H}_{5} \mathrm{Br}$; bromide of ethylen, $\mathrm{C}_{2} \mathrm{H}_{4} \mathrm{Br}_{2}$; bromide of methyl, $\mathrm{CH}_{3} \mathrm{Br}$; and bromoform, $\mathrm{CHBr}_{3}$. Bromide of ethylen and bromide of methyl are highly toxic when inhaled. Bromide of ethylen administered in mistake for bromide of ethyl is responsible for at least three deaths. Bromide of ethyl, known variously as bromethyl or ether bromatus, should be sent out by the manufacturer in hermetically sealed brown bottles, each containing only enough for a single administration and if any is left over it should not be used. The amount to be used at a single administration is now generally placed at from 10 to 30 grammes or by measure from two to six fluid drachms. 15 grammes measure exactly 10.5 cubic centimetres, or roughly three fluid drachms. More than one warning, however, has been given that 30 grammes (six fluid drachms) is too large a dose and may occasionally give rise to unpleasant symptoms, such as collapse and cyanosis, and that from 10 to 15 grammes is the largest amount that is needful or advisable. Most writers agree that prolonged anæsthesia by means of bromethyl is to be avoided and that if necessary the anæsthesia is to be continued with ether or chloroform.

The usual mode of giving bromide of ethyl is by means of a mask covered with impermeable cloth 'The mask should fit closely so as to exclude the air. Most authorities recommend that the entire amount to be administered should be poured at once on the mask and given at one dose. When the raised arm falls the patient is ready for any short operation. The inbalation is discontinued as soon as the patient is anæsthetised. This usually occurs within from half a minute to a minute and the patient wakes up in from one to three minutes. The face flushes moderately but the colour is not otherwise affected. The pulse, as a rule, is unaltered or slightly quickened. According to Silk the tension is much lowered. If anæsthesia lasting more than two or three minutes is required the bromide of ethyl mask is withdrawn the moment narcosis is established and the ether mask is immediately substituted. The bromide of ethyl anæsthesia then passes rapidly into ether anæsthesia without any struggling stage. Amongst the cases that are unsuitable for bromide of ethyl anæsthesia are very young children, very weak and anæmic persons, the subjects of Bright's disease or of fatty or otherwise degenerated heart, and alcoholic patients. Alcoholics are apt to become excited and do not readily go "under." As to vomiting there is great discrepancy, its occurrence varying in the statistics of different observers from 1 in 400 to 15 per cent. and even to 66 per cent. Dr. Kelly, who has the highest vomiting record, ascribes this result partly to the tender age of the majority of the patients ; partly to the fact that a very large proportion of his operations were for the removal of adenoids or tonsils, involving some bleeding into the throat or mouth; and partly to the disregard in dispensary practice of injunctions as to abstinence from food before operation. Sickness, when it occurs, is most usually after the anæsthesia is over.

Another drawback of bromide of ethyl anæsthesia is that the muscles do not usually become relaxed. For this reason in operations on the mouth a gag is inserted before the operation is begun. A period of excitement, sometimes violent, has occasionally been noted after the patient wakes. Hankel in 1897 had collected 21 cases of death. Three of these occurred in from 21 to 30 hours and one seven days after the anæsthesia. In two or three other cases transient fainting attacks or collapse appeared some time after the operation. More than a third of these deaths were due to causes that would be avoided nowadays, such as excessive doses (60,130, and 180 grammes), prolonged administration, impure or decomposed bromide of ethyl, or fatty heart. Respecting the remaining cases I bave not sufficient information to form an opinion. In spite of its drawbacks pure bromide of ethyl in proper doses properly administered to suitable cases appears to be at least as safe as ether.

Davos Platz.

\section{ON THE DETECTION OF LEAD IN URINE AND POST-MORTEM SPECIMENS.}

BY J. W. MELTOR, D. Sc., AND

FRANK SHUFFLEBOTHAM, M.A., M.B., B.C. C.NTAB.

THE detection of mineral poisons in organic matter is in many cases complicated by the fact that the metal is so intimately associated with the organic matter as to resist the action of the regular solvents. The organic matter must in consequence be first broken up in order that the metal may be extracted by the proper solvent. Boucher ${ }^{1}$ found that the lead was retained by organic matter so tenaciously that mere carbonisation of the organic matter was not sufficient. The lead can only be extracted by the solvent when the carbon is completely burnt to ash. There are two objections to this incineration. 1 . It is extremely difficult to oxidise all the carbon because the inorganic salts fuse and spread over the surface of the carbon protecting the latter from the oxygen of the air. 2. The high temperature necessary for the oxidation of the carbon is sufficient to volatilise some of the lead. This renders the method untrustworthy when dealing with small quantities of the metal. Fresenius and ron $\mathrm{Babo}^{2}$ oxidised the organic matter by boiling with a mixture of potassium chlorate and hydrochloric acid. Hydrochloric acid is not a good solvent for lead. It is necessary to filter the solution while hot in order to prevent the deposition of lead chloride on the filter. This method is said to give good results and the amount of lead may be determined by the electrolytic process of Lehmann. ${ }^{3}$ We have sought for lead in the kidney of Case 1 (the notes on which are given below) by the potassium chlorate and hydrochloric acid method, but the results were not very satisfactory. The process also occupied a considerable amount of time and required a good deal of attention. Pouchet ${ }^{4}$ proposed to destroy the organic matter by fusion with potassium hydrogen sulphate. Nikitin and Igefesky ${ }^{4}$ treated the material with ten times its weight of concentrated sulphuric acid. From two to five days' boiling are said to be neceseary for the complete destruction of the organic matter. Villiers ${ }^{4}$ employed a mixture of nitric acid and potassium permanganate. This, when followed by a treatment with a mixture of nitric and sulphuric acid, was found by Denig ès ${ }^{4}$ to give very good results. Orfila ${ }^{5}$ used ordinary nitric asid, but that is not sufficient for the dissolution of the lead. We found that a simple treatment of the organic matter with fuming nitric acid, as indicated below, gave very satisfactory results.

1 Boucher : Annales de Hygiène, vol. xli.

2 Fresenius and von Babo: Liebig's Annalen, vol. xlix., p. 287, 1844

3 Lehmann : Zeitschrift fir Physiologische Chemie, vol, vi., p. 1 .

4 Denigès: Bulletin de la Société Obimique de Paris, Series 3, vol. Xxv., No. 22 
Kidney.-A piece of kidney of 20 cubic centimetres capacity was cut up into about a dozen pieces. These were placed in an evaporating basin and about 50 cubic centimetres of fuming nitric acid were poured into the dish. Dense brown fumes of nitrogen oxides were evolved. When the action had subsided (in from two to three minutes) the dish was placed upon a sheet of asbestos and allowed to simmer over the Bunsen flame for about an hour. If the frothing appears in danger of running over the sides of the dish stirring with a glass rod or removal of the flame for a short time may be necessary. 25 cubic centimetres of the fuming acid were added at intervals of a quarter of an hour and this process was repeated three times. The destruction of the organic matter was so complete that the whole of the piece of kidney passed into complete solution. The solution was then evaporated down to a few cubic centimetres, neutralised with caustic soda, filtered, and treated with hydrogen sulphide. A dark-brown precipitate of lead sulphide was obtained. With potassium chromate a yellow precipitate of lead chromate was obtained with the same specimen of kidney which gave a negative result with the $\mathrm{KClO}_{3}-\mathrm{HCl}$ method of destroying the organic matter. Our reagents, dishes, \&c., were then examined with a blank test, but we found no lead.

Vrine.-We then sought the presence of lead in the urine of Cases 2, 3, and 4 (see below). Half a gallon of urine was evaporated down to dryness in each of two basins. In one basin the residue was heated until it was charred. Both residues were then treated separately with fuming nitric acid as just described. The uncharred residue passed into solution and on cooling deposited a white sediment. The mother liquor was neutralised and tested in the usual way. A brown precipitate of lead sulphide was obtained in Case 2 , while in Case 3 a well-marked black precipitate was obtained. The urine of Case 4 gave a negative result. The charred residue did not pass completely into solution and the tests for lead were not so well defined as when the residue was uncharred. This shows that care must be taken to prevent charring of the residue during evaporation.

CASE 1.-The patient was a man, aged 35 years. He had worked in lead processes all his life and had been a glost placer for 15 years. He was incapacitated from work for the ten months previous to his death. He first showed symptoms of plumbism two and a half years previous to his fatal illness, when he was affected with an illness similar to a violent bilious attack. He vomited and suffered from pains in the head. The pains recurred once a month and afterwards they were more frequent. Dr. R. H. Read of Hanley attended the patient during the last illness, the duration of which was a fortnight, and he found him suffering from symptoms of irritant poisoning affecting his nervous and digestive systems. The patient gradually became worse. The lower portion of the bowel became absolutely paralysed, and epileptiform convulsions supervened. Hiccough was a marked symptom. The cerebro-spinal canal was punctured in the lumbar region and 15 cubic centimetres of fluid were withdrawn with a view of relieving the convulsions, but it was without avail. At the post-mortem examination it was found that there was a marked blue line on the gums and there was evidence of chronic meningitis and of sclerosis of the brain tissue itself. There were ecchymoses in the mucous membrane of the stomach. The middle part of the bowel was distended with gas and the lower portion was very much contracted and filled with scybala. Both kidneys were granular, the left markedly so. The vermiform appendix was healthy. There was some congestion at the base of both lungs. The liver, heart, and spleen were perfectly healthy.

CASE 2.-The patient was a man, aged 24 years. He had been a house painter for the last 11 years. He had suffered from obscure symptoms of pains in the stomach, lassitude, and headache. He was clean in his habits but drank more alcohol than was good for him. He had a marked blue line on the gums. There was no albuminuria and no constipation. Since he changed his occupation to paper-hanging he has been quite well.

CASE 3.- The patient was a man, aged 33 years, who had worked in the lead all his life, first in the sagger house and afterwards as a glost placer. He suffered from paralysis of the arms. and colic, and was away from work for 11 days. He was pronouncedly anæmic and the blue line on the gums was well shown. There was albuminuria and the optic disc was normal.

CASE 4.- The patient was a man, aged 66 years. He had been a glost placer for 40 years, but for the last seven years had been a caretaker. While working with lead he suffered from two attacks of colic. He also had several attacks of muscular rheumatism and for a great number of years had had chronic bronchitis. The blue line on the gums was still seen, although he had been away from the lead so long.

Conclusions. - We consider the fuming nitric acid test as employed by us to be superior to the tests we have mentioned at the beginning of this parer on account of its greater delicacy, easy manipulation, and the short time required to carry out the test. It is obvious that this process can be easily adapted to the usual methods for quantitative determinations.

We thank the Headmaster of the Newcastle-under-Lyme High School for placing the resources of the chemical laboratory at our disposal.

Newcastle-under-Lyme.

\section{A CASE OF UMBILTCAL CALCULUS.}

BY J. R. HARPER, M.R.C.S. ENG, L.R.O.P. LOND., HONORARY SURGEON, NORTH DEVON INFIRMARY;

With a Nete on its Histology by

\section{G. SELIGMANN, M.B., M.R.C.P. LoND.}

THE patient was a man, aged 46 years, who had been a soldier. When in Egypt in 1882 he had a severe attack of cholera; other than that he had always enjoyed good health. In the first week of July, 1902, he was worried with a slight purulent discharge from the umbilicus, around the circumference of which for about a quarter of an inch was a moist weeping eczema. He complained of no pain, only of the discomfort which was occasioned by his shirt sticking to his abdomen. There was no offensive smell from the discharge, A simple local application relieved him and for a few days he was quite comfortable. About ten days after, however, in lifting a cask, he seems to have strained himself and to have hurt his left side. At first he did not pay much attention to it, but finding that he was getting worse he again presented himself for treatment. It was then found that he had a good deal of tenderness and muscular rigidity in the left iliac region. He was ordered home to bed and hot fomentations were applied. In a few days it became apparent that an abscess was forming in the abdominal wall which was draining through the umbilicus, the discharge from which was most offensive. The man became acutely ill, rapidly losing tlesh and being worn out with the pain and the discharge from the navel.

On July 26th two incisicns were made into the abscess, which now reached from the umbilicus to Poupart's ligament on the left side, one incision being made immediately to the left of the umbilicus and at the same level and the other just on the outside of the left linea semilunaris. A large quantity of very offensive pus was evacuated and the abscess cavity was found to extend to Poupart's ligament on the left side. At the bottom of the cavity behind the rectus muscle a stene was found of about the size of a walnut. This was forwarded to Dr. C. G. Seligmann whose report is given below. By August 25th the wounds were well healed and the patient had much improved in health. The patient seems to have suffered no pain or inconvenience whatever until suppuration commenced. $\mathrm{He}$ is an intelligent man and says that he can only account for it by assuming that it must have arisen from neglect while on active service, when he was several weeks without having a chance of thoroughly washing himself or of changing his clothes.

The literature of umbilical calculus is so scanty that it seems worth while recording this case. The text-books of surgery make no mention of it; the only references are apparently two cases-one published by Mr. S. G. Shattock, which is referred to below, and another recorded by Mr. Dean in the "Anomalies and Curiosities of Medicine" (Gould and Pyle)

Report by Dr. SELIGMANr. - The specimens received consist of two irregular masses of a brownish colour. The larger mass is roughly conical with a truncated apex and measures about 14 millimetres in its chief diameter 